\title{
The Factorial Design with the type of Plackett-Burman to Determine the Optimization in the Brown Rice Production Process
}

\author{
B. Surapong ${ }^{1}$, B. Phiraphan ${ }^{2}$, B. Wiboonluk ${ }^{3}$ \\ ${ }^{1}$ Department of Industrial Technology Education, Faculty of Engineering, Rajamangala University of Technology \\ Lanna, Thailand, pong_pang49@yahoo.com, surapongb@edu.rmutl.ac.th \\ ${ }^{2}$ Department of Industrial Technology Education, Faculty of Engineering, Rajamangala University of Technology \\ Lanna, Thailand, foundry18@yahoo.com \\ ${ }^{3}$ Department of Student development Division, Rajamangala University of Technology Lanna. 128 Huay kaew \\ Road, Muang District, Chiang Mai 50300, Thailand, Viboonluk_bp@ @otmail.com
}

\begin{abstract}
This research aims to improve the paddy husking process by experimenting with Hom Nin rice. By designing a factorial experiment, placket-Berman type, to determine the optimum value in the husking process to obtain the lowest and best percentage of broken rice in the husking process. By controlling factors two variables are the spindle of speed, and the clearance of rubber for the two rubbers. The process model was formulated based on analysis of variance (ANOVA) and regression of coefficient. The results showed that both variables were $p$ value is greater than alpha value $(0.278>0.05)$. The percentage of broken rice was at 8.76 at the confidence level 95 percent significance between the two factors That are, the spindle of speed is equal to $1,420 \mathrm{rpm}$ and the clearance rubber between the two rubbers are equal to 1 millimeters.
\end{abstract}

Key words: Analysis of variance (ANOVA), regression of coefficient, optimization, factorial design, Placket-Burman, brown rice, Hom Nin rice

\section{INTRODUCTION}

The quality of peeled rice is depending on many factors such as rice strain, the rate of feeding, clearance between a rubber to rubber cylinder and paddy moisture content which usually are controlled not to be exceed 14\% [1], [2]. In rice milling, the bran layers and germ removed during polishing are high in fiber, vitamins and minerals as well as protein. Their removal results in loss of nutrients, especially in substantial losses of B vitamins. Polishing rice reduces the thiamin content of rice by over $80 \%$. Parboiled rice is therefore higher in B vitamins than raw milled rice [3].

The enhancement of rice supply is another advantage of brown rice relative to polished or white rice. Post-harvest researchers say that the milling recovery in brown rice is $10 \%$ higher than polished rice [4]. There is the other benefit of brown rice - economics the fuel savings in milling is 50-60\% because the polishing and whitening steps are eliminated. It follows that the milling time is also shortened; labor is less; and the cost of equipment (if the mill is dedicated to brown rice) is much lower because the miller doesn't have to install polishers and whiteners [5].

Milling strips off the bran layer, leaving a core comprised of mostly carbohydrates [6]. In this bran layer resides nutrients of vital importance in the diet, making white rice a poor competitor in the nutrition game the following chart shows the nutritional differences between brown and white rice. Fiber is dramatically lower in white rice, as are the oils, most of the $\mathrm{B}$ vitamins and important minerals [7]. Brown rice (hulled rice) is composed of surface bran (6-7\% by weight), endosperm (E90\%) and embryo (2-3\%), [8]. White rice is referred to as milled, polished or whitened rice when $8-10 \%$ of mass (mainly bran) has been removed from brown rice [7]. During milling, brown rice is subjected to abrasive or friction pressure to remove bran layers resulting in high, medium or low degrees of milling depending on the amount of bran removed [7]-[10]. Milling brings about considerable loss of nutrients and affects the edible properties of milled rice [7]-[10]. As most cereals, rice does not show a homogeneous structure from its outer (surface) to inner (central), [11]. As a consequence, information on the distribution of nutrients will greatly help in understanding the effect of milling and aid in improving sensory properties of rice while retaining its essential nutrients as much as possible [12].

Therefore, the purpose of this second research is to generate between clearance of rubber and spindle of speed using Design of Experiment (DOE) by Factorial Design with type of Plackett-Burman design in order to generate the suitable factors. And the parameters are significant at the confidence level Ninety five percent per percentage of broken rice with Hom Nin test. 
B. Surapong et al., International Journal of Emerging Trends in Engineering Research, 9(7), July 2021, 859 - 864

\section{EXPERIMENTAL DESIGN}

\subsection{Factorial Design of Experiments}

Optimum conditions are decided by changing several factors at once and using different levels of these factors. Factorial designs are widely applied in the experiments that are taking into account several factors where it is necessary to study the interaction effect of factors on the response [13]. $2^{k}$ factorial design of experiments needs a smaller number of experiments for several factors; thus, materials and time used are slightly reduced [14],15]. When factorial design methods applied to experiments of a process, mathematical models are derived through obtained variance analysis tables. Experiments are chosen randomly to prevent partiality of researchers [16].

The Factorial Design with type of design Placket-Burman design describes which factor shows more impact and influences the variation of one factor on the other factors [17]. The two factors; spindle of speed (SS) and the rubber of clearance (CL), respectively were varied at two levels as given in (see Table 1) to investigate their effects on response.

Table 1: Factors and levels for brown rice production experiment

\begin{tabular}{|lccc|}
\hline Parameter & Variable & Lower Limit & Upper Limit \\
\hline $\begin{array}{l}\text { Spindle } \\
\text { of speed, SS }\end{array}$ & $\mathrm{X}_{1}(\mathrm{RPM})$ & 1,420 & 1,460 \\
$\begin{array}{l}\text { Rubber of } \\
\text { clearance, } \mathrm{CL}\end{array}$ & $\mathrm{X}_{2}(\mathrm{~mm})$. & 1.0 & 1.2 \\
\hline
\end{tabular}

Table 2: Design matrix for DOE $2^{k}$ factorials

\begin{tabular}{|c|c|c|c|c|c|}
\hline Run Order & Pt Type & Blocks & $\mathrm{X}_{1}$ & $\mathrm{X}_{2}$ & $\%$ Broken \\
\hline 1 & 1 & 1 & 1 & -1 & 23.52 \\
\hline 2 & 1 & 1 & 1 & -1 & 23.61 \\
\hline 3 & 1 & 1 & $-1-$ & 1 & 10.10 \\
\hline 4 & 1 & 1 & 1 & -1 & 23.58 \\
\hline 5 & 1 & 1 & -1 & 1 & 17.03 \\
\hline 6 & 1 & 1 & -1 & -1 & 11.25 \\
\hline 7 & 1 & 1 & -1 & 1 & 12.10 \\
\hline 8 & 1 & 1 & 1 & 1 & 27.50 \\
\hline 9 & 1 & 1 & 1 & -1 & 22.45 \\
\hline 10 & 1 & 1 & 1 & 1 & 28.73 \\
\hline 11 & 1 & 1 & -1 & 1 & 19.15 \\
\hline 12 & 1 & 1 & -1 & -1 & 10.55 \\
\hline 13 & 1 & 1 & 1 & 1 & 27.95 \\
\hline 14 & 1 & 1 & -1 & 1 & 18.85 \\
\hline 15 & 1 & 1 & -1 & -1 & 11.87 \\
\hline 16 & 1 & 1 & -1 & -1 & 8.89 \\
\hline 17 & 1 & 1 & -1 & 1 & 9.97 \\
\hline 18 & 1 & 1 & 1 & -1 & 23.76 \\
\hline 19 & 1 & 1 & -1 & -1 & 8.76 \\
\hline 20 & 1 & 1 & 1 & 1 & 27.25 \\
\hline 21 & 1 & 1 & -1 & -1 & 9.21 \\
\hline 22 & 1 & 1 & 1 & -1 & 19.50 \\
\hline 23 & 1 & 1 & -1 & 1 & 21.35 \\
\hline 24 & 1 & 1 & 1 & 1 & 21.15 \\
\hline
\end{tabular}

Table 2: (cont.) Design matrix for DOE 2k factorials

\begin{tabular}{|lllllc|}
\hline Run Order & Pt Type & Blocks & X1 & X2 & \% Broken \\
\hline 25 & 1 & 1 & 1 & 1 & 28.21 \\
\hline 26 & 1 & 1 & 1 & -1 & 20.95 \\
\hline 27 & 1 & 1 & -1 & 1 & 19.68 \\
\hline 28 & 1 & 1 & -1 & -1 & 12.79 \\
\hline 29 & 1 & 1 & -1 & 1 & 19.56 \\
\hline 30 & 1 & 1 & -1 & 1 & 16.56 \\
\hline 31 & 1 & 1 & 1 & 1 & 28.22 \\
\hline 32 & 1 & 1 & 1 & 1 & 28.35 \\
\hline 33 & 1 & 1 & 1 & -1 & 23.75 \\
\hline 34 & 1 & 1 & 1 & 1 & 28.45 \\
\hline 35 & 1 & 1 & 1 & -1 & 23.66 \\
\hline 36 & 1 & 1 & -1 & -1 & 8.78 \\
\hline
\end{tabular}

The $2^{k}=36$ factorial with three replicated treatment combinations were performed. Note that 36 samples were made at the coded treatment combination $(0,0)$. The observed percentage of broken rice ranged from $8.76 \%$ to $28.73 \%$. Table 2 presents the results for all $2^{k}=36$ runs, run order by response. Therefore, thirty- six observations were taken in all to employ Factorial Design type of Plackett - Burman Design as shown in (see Table 2). Throughout the experiment it was assumed that: the factor is fixed; the design was completely randomized and the usual normality assumptions of the data were satisfied [20], [21].

\subsection{Statistical Methods and Software}

The analysis and results of the experimental design were studied and interpreted by MINITAB RELEASE 19.00 (PA, USA licensed to Department of Industrial Engineering, Faculty of Engineering, Rajamangala University of Technology Lanna, Chiang Mai, Thailand) statistical software to estimate the response of the dependent variable. The response curves and contour plots are also generated. After production process of brown rice, the response was calculated and analyzed using regression coefficient analysis and analysis of variance (ANOVA) [20], [21].

\subsection{Hypothesis}

Definition of Statistical hypothesis

Statistical hypothesis that are evaluated by appropriate statistical techniques.

There are two hypotheses involved in hypothesis testing

- Null hypothesis $H_{0}: \mu_{1}=\mu_{2} \quad$ (there is not significantly different in mean the percentage of broken rice).

- Alternative hypothesis $H_{1}: \mu_{1} \neq \mu_{2}$ (at least one different in mean the percentage of broken rice).

The level of significance $(\alpha)$ is a probability and, in fact, is a probability of rejecting a true null hypothesis.

The level of significance $(\alpha)$ are as follows:

If the p-value $<\alpha$, then reject $H_{0}$ that means there are at least one level significantly different. 
B. Surapong et al., International Journal of Emerging Trends in Engineering Research, 9(7), July 2021, 859 - 864

If the $p$-value $\geq \alpha$, then failed to reject $H_{0}$ that means no significantly different [20], [21].

\section{RESULTS AND DISCUSSION}

\subsection{Results}

The experimental design of the Berman packet method was controlled by two factors: The speed of rotation and the clearance between the two rubbers. The best results were obtained and the most suitable was the percentage of broken rice equal to 8.76 at which rpm is at 1420 RPM, and clearance between the two rubber is 1- millimeter. The level of 19 in (see Table 1 and 2) respectively.

From the analysis of variance, it was found that the adjusted decision coefficient is at 84.57 percent. A confidence level of $95 \%$ found that the two factors interacted together: The spindle of speed, and the clearance of rubber between the two tires is $p$ equal to 0.278 which is greater than the value of 0.05. shown in (see Table 3)

From this experimental design, it was found that the important variables involved in the experiment were relative humidity outside, workers, weather conditions, and the experimental unit but the working group has tried to consider such factors to be acceptable. It can be seen from the result that the percentage of broken rice was equal to 8.76 and five more experiments confirmed the results at the spindle of speed equal to 1420 RPM, with the clearance between the two-rubber equal to 1-millimeter values averaged between 8.67 to 8.81 respectively.

Table 3: Analysis of variance

\begin{tabular}{|c|c|c|c|c|c|}
\hline \multicolumn{1}{|c|}{ Source } & DF & Adj SS & Adj MS & F-value & P-value \\
\hline Model & 3 & 1476.8 & 489.21 & 69.53 & 0.000 \\
\hline Linear & 2 & 1451.0 & 723.15 & 111.23 & 0.000 \\
\hline SS & 1 & 1187.1 & 1146.3 & 168.26 & 0.000 \\
\hline CL & 1 & 277.69 & 276.54 & 39.22 & 0.000 \\
\hline 2-Way Interactions & 1 & 6.62 & 6.62 & 6.62 & 0.278 \\
\hline SS*CL & 1 & 6.62 & 6.62 & 6.62 & 0.278 \\
\hline Error & 32 & 229.41 & 6.74 & & \\
\hline \multirow{2}{*}{ Total } & 35 & 1621.6 & & & R-sq \\
\hline \multicolumn{2}{|c|}{ Model summary } & $\mathrm{S}$ & $\mathrm{R}-\mathrm{sq}$ & $\mathrm{R}$-sq(adj) & \\
\cline { 2 - 7 } & & 2.5789 & $85.78 \%$ & $84.57 \%$ & $84.15 \%$ \\
\hline
\end{tabular}

\subsection{Hypothesis Testing}

An alternative decision rule using the $p$ - value definition. The $p$-value is defined as the smallest value of $\alpha$ for which the null hypothesis can be rejected.
If the p-value is less than or equal to $\alpha$, we reject the null hypothesis $(p<\alpha)$.

If the p-value is greater than $\alpha$, we do not reject the null hypothesis $(p \geq \alpha)$.

Consistent with the first article is optimization of Factorial Design with the type of Plackett-Burman design to study the effects of brown rice production process: first step experiment.

\subsubsection{Spindle of Speed Factor}

For the percentage of broken rice, the value of $\mathrm{p}$ was 0.000 . Thus, the conclusion is rejecting $H_{0}$, which means there are significant differences between the levels in the p. The response is shows that the response significant effect on production process of brow rice.

\subsubsection{Clearance Factor}

For the percentage of broken rice, the value of $p$ was 0.000 . Thus, the conclusion is rejecting $H_{0}$, which means there are significant differences between the levels in the $p$. The response is shows that the percentage of broken rice significant effect on production process of brown rice.

\subsubsection{Spindle of Speed and Clearance (Two-Way Interaction)}

For interaction with the spindle of speed and clearance the value of $p$ was 0.278 . So, the conclusion is accepting $H_{0}$, which means there are no significant differences between the levels spindle of speed and clearance. This suggests that the interaction with the spindle of speed and clearance effect on production process of brown rice. The differences of broken rice between level of each factor as shown in Figure 1 and mean of broken rice of each level shown in (see Table 3 and see Table 4).

While the remaining interaction the $p \geq \alpha$ which means there is significant difference between the level of the spindle of speed and clearance interaction. This suggests that the spindle of speed, and clearance are significant effect of broken rice in production process of brown rice. Consistent with the first article is optimization of factorial design with the type of Plackett-Burman design to study the effects of brown rice production process: first step experiment [20],[21].

Figure 1 shows the factorial plot versus mean response of the two factors $\left(X_{1}\right.$ and $\left.X_{2}\right)$ the percentage of broken rice. The effect of a factor is the change in the percentage of broken rice produced by the change in level of factor. This is frequently called a main effect as it refers to the primary factor of interest in the experiment [18]. Please note that the statistical 
significance of a factor is directly related to the length of the vertical line [19].

\subsection{Discussion}

Applying experimental design principles by of Factorial Design with the type of Plackett-Burman design to assist in the paddy husking process to determine the minimum and optimal percentage of broken rice. In this research, two variables were studied: spindle of speed and the clearance of rubbers between the two rubbers. That was found that the optimal value was 8.76 percent. After obtaining the desired answer, the experiment was repeated five times. has an average of 8.67 to 8.81 percent respectively shows that the desired target value is significant in the confidence level of 95 percent.

Table 4: Code coefficients $2^{\mathrm{k}}$ design

\begin{tabular}{|l|c|c|c|c|c|c|}
\hline \multicolumn{1}{|c|}{ Term } & Effect & Coef & SE Coef & T-Value & P-Value & VIF \\
\hline Constant & & 22.05 & 0.376 & 44.21 & 0.000 & \\
\hline SS & 10.798 & 6.245 & 0.376 & 12.78 & 0.000 & 1.00 \\
\hline CL & 4.787 & 3.324 & 0.376 & 5.16 & 0.000 & 1.00 \\
\hline SS*CL & -0.897 & -0.379 & 0.376 & -1.11 & 0.296 & 1.00 \\
\hline
\end{tabular}

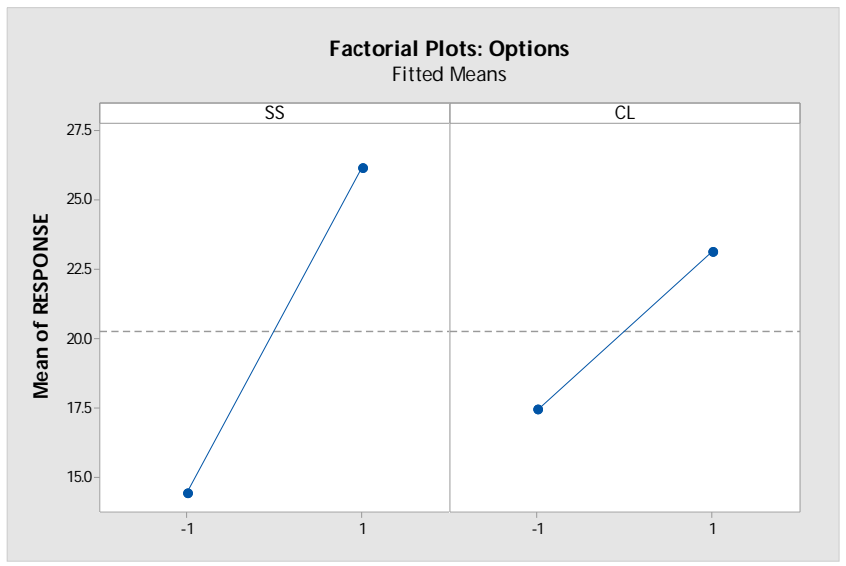

Figure 1: Cube plots: options of main effects for the broken rice

Analysis of variance is a statistical method that partitions the total variation into its component parts each of which is associated with a different source of variation [17]. The interaction effects are easily estimated and tested by using the usual ANOVA. The ANOVA results of the response were shown in (see Table 2). The sum of the squares used to estimate factors affect and Fisher's $F$ ratios (defined as the ratio of mean square effect and the mean square error) and $p$ values (defined as the level of significance leading to the rejection of the null hypothesis) were also represented.

The individual and interaction effects was given by the contour plot of the percentage of response the effects between
SS and CL in as shown in Figure 2.

Consistent with the first article is optimization of factorial design with the type of Plackett-Burman design to study the effects of brown rice production process: first step experiment and second step experiment respectively [20], [21].

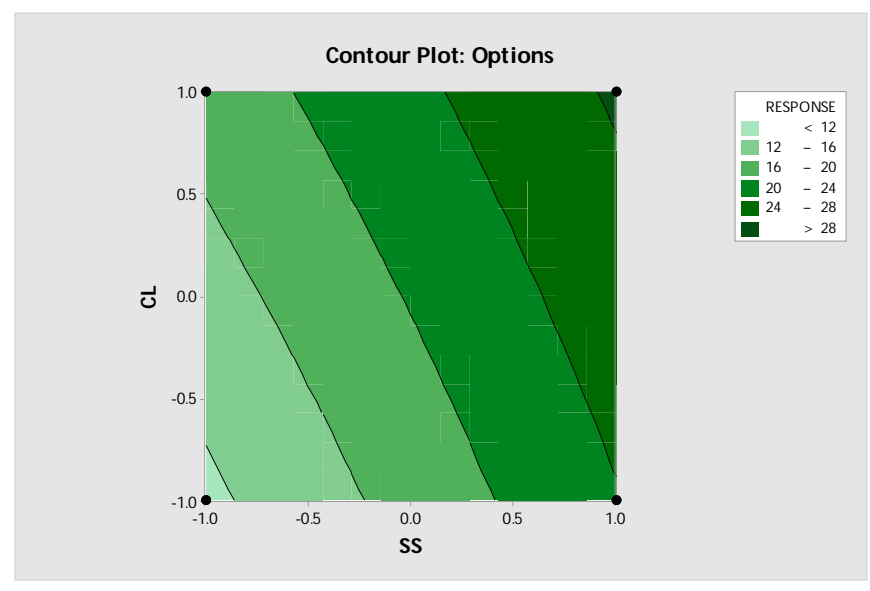

Figure 2: Contour plot: options of response

\section{CONCLUSIONS}

Applying Factorial Design principles with the type of Pleckett- Burman to the brown rice production process, the researchers conducted a significant experiment at a confidence level of ninety-five percent. From the variance analysis at alpha 0.05 , The two coefficients were co-reactive for the spindle of speed, and the clearance between the two rubbers at 0.278 , and the adjusted decision coefficient was $84.57 \%$, and the percentage of broken rice is equal to 8.76, which is a very small value. It shows that the percentage of good rice is high. But there were some contributing factors during the trial, such as external relative humidity, labor, weather conditions and the equipment to be tested such co-factors need to be taken into account when experimenting. which cannot be controlled.

In this experiment, the control factors consisted of a spindle of speed and the clearance between the two rubbers. The most suitable value is the spindle of the speed, and the clearance between the two rubber is equal the percentage of broken rice is 8.76 .

Where the adjusted decision coefficient is at $84.57 \%$ thus, the brown rice production process has a very little percentage of broken rice. But on the contrary, the percentage of rice is more good. It shows that the application of experimental design principles with the packet type factorial design method Berman had significant convictions. 
After the experiment, it was found that the difference between the first article and the second article was the percentage of good rice and percentage of broken rice respectively. The article that one has the best good rice percentage is 91.24 , as for this article, the percentage of broken rice is the best equal to 8.76 .

The application of experimental design techniques using Factorial Design with a type of Plackett-Burman Design showed widespread confidence in the manufacturing industry and the ability to analyze and know the variables studied. Significant desired results. The experimental design can therefore be described with great statistical certainty as well as being able to expand results leading to actual use.

In this research, Hom Nin rice varieties were selected. from the same plantation control, the humidity of paddy between twelve to fourteen percent, and such paddy varieties must be clean and free from dust particles that are contaminated with paddy. Make the most suitable and affect rubber does not damage the rubber faster than scheduled.

Hom-nin rice is one of Thailand's varieties, fragrant, and highly nutritious. For this research, all were selected from the same source. The tested Hom Nin rice was very clean and free of any impurities in the paddy. In terms of shellers, they are effective for households, easy to move. There is a production control at every step, the result. Therefore, the percentage of broken rice is very low. Compared to the machines that are available in the general market. In this research, a better percentage 35 percent

According to [20], [21] both articles aimed to determine the optimal value of organic rice. The results of the two papers were not significantly different because they used the first and second-stage factorial designs with the type of Placket Berman experimental designs. This research section uses the same principles as the two articles mentioned. But different in the part of the rice varieties that were tested for efficiency. In this research, Hom Nin rice varieties were selected. It was found that the percentage of broken rice was the least at 8.76 .

\section{ACKNOWLEDGEMENTS}

Financial support department of Industrial technology education, faculty of Engineering RMUTL: Rajamangala University of Technology Lanna, Chiang Mai, Thailand is gratefully acknowledged.

\section{REFERENCES}

1. S. Bangphan and S. Lee. Modeling material mixtures to replace of rice polishing cylinder, Proceeding of the Conference of Industrial Engineering, IE network conference, Bangkok, Thailand, 17-19 December 2006.

2. S. Bangphan, S. Lee and S. Jomjunyong. Development of the Alternative composite material for rice polishing cylinder, Proceeding 8th, Conference APIEMS \& CIIE 2007, Industrial Engineeris, Kaohsiung, Taiwan, 9-12 December 2007.

3. Oh. C.H. and S.H. Oh. Effects of germinated brown rice extracts with enhanced levels of GABA on cancer cell proliferation and apoptosis, Journal of Medical Food, 2004, vol.7, no1.

4. Garrow J.S. et al . Human nutrition and dietetics, Harcourt Publishers, London, 2000.

5. Rogelio V. Cuyno. The national campaign to combat hidden hunger through brown rice paper presented during consultative meeting on nutritional aspect of brown rice, at Food \& Nutrition Research Institute., Manila Philippines,2003.

6. S. Bangphan., P. Bangphan, and T.Boonkang. Implementation of response surface methodology using in small brown rice peeling machine : part $\mathbf{I}$, World Academy of Science, Engineering and Technology; ICIKM 2013 : International Conference on Information and Knowledge Management, Barcelona, Spain, 27-28 February 2013.

7. Wood Rebecca. The whole foods encyclopedia, New York, NY: Prentice-Hall Press, 1988.

8. Chen H. and Siebenmorgen T.J. Effect of rice thickness in degree of milling and associated optical measurements, Cereal Chemistry, 1997, no. 74, pp. 821-825.

9. Chen H., Siebenmorgen T.J. and Griffin, K.

Quality characteristics of long-grain rice milled in two commercial systems, Cereal Chemistry, 1998, vol. 75, 560-565.

10. Kennedy G., Burlingame B. and Nguyen N. Nutrient impact assessment of rice in major rice-consuming countries, International Rice Commission Newsletter, 2002, no.51, pp.33-41.

11. Itani T., Tamaki M., Arai E. and Horino T. Distribution of amylose, nitrogen, and minerals in rice kernels with various characters, Journal of Agricultural and Food Chemistry,2002, vol. 50, pp. 5326-5332.

12. Jianfen Liang et al. Milling characteristics and distribution of phytic acid and zinc in long-,mediumand short-grain rice, Journal of Cereal Science, 2008, vol. 48, pp. 83- 91.

13. K. E. Lee, N. Morad, T. T. Teng, and B. T. Poh. Factorial experimental design for reactive dye flocculation using inorganicorganic composite polymer, APCBEE Procedia, 2012, vol. 1, pp. 59-65. 
B. Surapong et al., International Journal of Emerging Trends in Engineering Research, 9(7), July 2021, $859-864$

14. G. Annadurai, R.-S. Juang, and D.-J. Lee. Factorial designanalysis for adsorption of dye on activated carbon beads incorporated with calciumalginate, Advances in Environmental Research, 2002, vol. 6, no. ,pp. 191-198.

15. V. Ponnusami, V. Krithika, R. Madhuram, and S. N. Srivastava. Biosorption of reactive dye using acidtreated rice husk: factorial design anlysis, Journal of Hazardous Materials, 2007, vol.142, no.1-2,pp.397-403.

16. N. Özbay, A. F. YargJç, R. Z. Yarbay-Fahin, and E. Önal. Full Factorial Experimental design analysis of reactive dye removal by carbon adsorption, Journal of Chemistry, Volume 2013, Article ID 234904, 13 pages, 2013.

17. Y. Safa and H. N. Bhatti. Adsorptive removal of direct textile dyes by low cost agricultural waste: application of factorial design analysis, Chemical Engineering Journal, 2011, vol. 167, no. 1, pp. 35-41.

18. A. Rathinam, J. R. Rao, and B. U. Nair. Adsorption of phenol onto activated carbon fromseaweed: determination of the optimal experimental parameters using factorial design, Journal of the Taiwan Institute of Chemical Engineers, 2011, vol. 42, no. 6, pp. 952-956.

19. D. Bingol,N. Tekin, andM. Alkan. Brilliant yellow dye adsorption onto sepiolite using a full factorial design, Applied Clay Science, 2010, vol. 50, no. 3, pp. 315-321.

20. B.Surapong and P.Suwattanarwong. Optimization of factorial design with the type of plackett-burman design to study the effects of organic rice production process: first step experiment, International Journal of Advanced Trends in Computer Science and Engineering, 2021, vol. 10, no. 3, May-June, pp.2080-2084.

21. P.Suwattanarwong and B.Surapong. Optimization of factorial design with the type of plackett-burman design to study the effects of organic rice production process: second step experiment, International Journal of Advanced Trends in Computer Science and Engineering, 2021, vol. 10, no. 3, May-June, pp.2085-2089. 